\title{
Corticosteroid-induced ocular hypertension. I. Prevalence in closed-angle glaucoma
}

\author{
A. O. AKINGBEHIN \\ From the Department of Ophthalmology, University of Liverpool, St Paul's Eye Hospital, \\ Old Hall Street, Liverpool L3 9PF
}

SUMMARY Forty-eight eyes with closed-angle glaucoma and 31 eyes at risk were subjected to corticosteroid provocative tests. $65 \%$ and $9.7 \%$ respectively responded with a change in pressure $\geq 6 \mathrm{mmHg}$. The responses of the 2 groups were compared with each other and also, with the corticosteroid pressure response in normal eyes. The differences in behaviour between the eyes with closed-angle glaucoma and eyes at risk, and the eyes with closed-angle glaucoma and normal eyes, are statistically highly significant. The implications of this are discussed. The prevalence of corticosteroid-induced ocular hypertension in closed-angle glaucoma is higher than previously reported.

Corticosteroid-induced ocular hypertension is a well recognised entity which has been demonstrated and reported by several observers in patients with primary open-angle glaucoma, their siblings and children, and in glaucoma suspects and apparently normal individuals. ${ }^{1-11}$

There are few published data on the corticosteroid response of patients with closed-angle glaucoma. ${ }^{12-14}$ This study investigates the prevalence of corticosteroid pressure response in 2 groups of eyes related to closed-angle glaucoma.

\section{Material and methods}

Two groups of eyes were subjected to corticosteroid provocative testing.

Group $A$ consisted of $\mathbf{4 8}$ eyes that had sustained closed-angle glaucoma and had been treated by peripheral iridectomy at least 6 months before the beginning of the study. The types of closed-angle glaucoma sustained were classified into chronic, acute, and intermittent.

Six out of the 48 eyes required antiglaucoma therapy to control the intraocular pressure, and the pressures had been well controlled with the same treatment (drops only) for at least 6 months without any change. The antiglaucoma therapy was continued without change throughout the corticosteroid provocative test.

Correspondence to Mr A. O. Akingbehin, FRCS.
Group B consisted of 31 eyes at risk of developing closed-angle glaucoma (because the fellow eyes had had a spontaneous episode of closed-angle glaucoma). These eyes were admitted into the study only if they satisfied the following criteria: (1) prophylactic peripheral iridectomy performed with an uneventful postoperative period at least 6 months prior to start of study; (2) contralateral eye had a spontaneous episode of closed-angle glaucoma; (3) open angles as assessed by a slit beam and also gonioscopically; (4) no peripheral anterior synechiae; (5) no pseudoexfoliation of the lens capsule; (6) no significant amount of pigment in angles; (7) normal discs; (8) normal visual fields-central and peripheral; (9) intraocular pressure by applanation, outflow facility, and $\mathrm{Po} / \mathrm{c}$ ratio all within normal limits; (10) patient not on oral hypotensive agent, namely, acetazolamide.

\section{CORTICOSTEROID PROVOCATIVE TEST}

This was performed as follows.

1. Patient education: $(a)$ risks of test; $(b)$ importance of $100 \%$ compliance. Patients were asked to keep a record of missed drops. Those who missed 24 out of a total of 168 administrations over a 6-week period (equivalent to missing one day's administration/week) were judged to have complied poorly, and the test therefore to be invalidated if negative.

2. Pretest detailed examination of the eye for best visual acuity, herpetic corneal disease, pupillary 
Table 1 Features of the samples

\begin{tabular}{lcc}
\hline & $\begin{array}{l}\text { Closed-angle } \\
\text { glaucoma eyes }\end{array}$ & Eyes at risk \\
\hline Total no. of eyes & 48 & 31 \\
No. of patients & 41 & 31 \\
Bilateral cases & 7 & - \\
Eyes provoked: right & 23 & 16 \\
& 25 & 15 \\
Age range (years) & $49-79$ & $49-79$ \\
Average age of patient & $67 \cdot 4$ & 69 \\
Standard deviation & $8 \cdot 4$ & $8 \cdot 0$ \\
Sex: Male & 10 & 6 \\
$\quad$ Female & 31 & 25 \\
Race: Caucasians & 48 & - \\
$\quad$ Negroes & - & - \\
\hline
\end{tabular}

diameter, pseudoexfoliation, lens changes, ophthalmoscopy, field studies, gonioscopy for peripheral anterior synechiae and pigment, assessment of angles by the slit beam.

3. Initial applanation tonometry and tonography, time of day being noted.

4. The patients were instructed to instil, after shaking the bottle, one or 2 drops of the corticosteroid preparation into the lower fornix 4 times a day.

5 . The preparation used was dexamethasone $0.1 \%$; preservative benzalkonium chloride $0.01 \%$; vehicle hydroxypropyl methylcellulose $0.5 \%$; available commercially as Maxidex.

6. The patients were seen at weekly intervals at about the same time of day for applanation tonometry and tonography; on occasions after 2 weeks.

7. The test was terminated after 6 weeks with a final applanation tonometry and tonography unless a high response (intraocular pressure checked 3 times) was observed before then.

8. All provocative test resulting in or terminated because of a high response were treated with a single dose of gutt. pilocarpin. $2 \%$ to the involved eye and a single oral dose of acetazolamide (Diamox Sustet) $500 \mathrm{mg}$. The intra-ocular pressure was checked again in 24 hours. If the intraocular pressure had not returned to the pretest level or a reasonably lower pressure, the above treatment was repeated and the patient seen again after $\mathbf{2 4}$ hours. The probability of this happening was less than $1 \%$.

9. The patients with a positive response were seen one or 2 weeks after termination of provocative test for a post-test examination which included best visual acuity, lens changes, ophthalmoscopy, and applanation tonometry. Field studies and tonography were done as indicated.

10. A positive corticosteroid provocative test was defined as a change in intraocular pressure greater than $5 \mathrm{mmHg}$.

\section{Results}

The features of the 2 groups studied are summarised in Table 1. The results of corticosteroid provocative tests in closed-angle glaucoma eyes and eyes at risk are shown in Tables 2 and 3 respectively.

\section{GROUP A}

The corticosteroid provocative test in the 48 eyes with closed-angle glaucoma resulted in a $65 \%$ positive response: $50 \%$ (i.e., 24 eyes) had an intermediate response (a change in intraocular pressure $(\Delta P)$ of 6-15 $\mathrm{mmHg}$ ) and $15 \%$ (i.e., 7 eyes) a high response $(\Delta \mathrm{P} \geq 16 \mathrm{mmHg})$.

The type of closed-angle glaucoma sustained was

Table 2 Results of corticosteroid provocative test in eyes of 48 patients with closed-angle glaucoma

\begin{tabular}{|c|c|c|c|c|c|c|c|c|}
\hline & \multicolumn{3}{|l|}{ Initial } & \multicolumn{3}{|l|}{ Final } & \multirow{2}{*}{$\begin{array}{l}\Delta P \\
P_{2}-P_{1}\end{array}$} & \multirow{2}{*}{$\begin{array}{l}\Delta C \\
C_{2}-C_{1}\end{array}$} \\
\hline & $P_{1}$ & $C_{1}$ & Po/c & $P_{2}$ & $C_{2}$ & Po/c & & \\
\hline $\begin{array}{l}\text { Mean } \\
\text { SEM }\end{array}$ & $\begin{array}{l}19 \\
0.48\end{array}$ & $\begin{array}{l}0.23 \\
0.01\end{array}$ & $\begin{array}{r}102 \\
6.8\end{array}$ & $\begin{array}{c}27 \cdot 4 \\
1 \cdot 17\end{array}$ & $\begin{array}{l}0.19 \\
0.02\end{array}$ & $\begin{array}{c}226 \\
26 \cdot 7\end{array}$ & $\begin{array}{c}+8.4 \\
0.86\end{array}$ & $\begin{array}{r}-0.04 \\
0.01\end{array}$ \\
\hline
\end{tabular}

$\mathrm{P}=$ intraocular pressure. $\mathrm{C}=$ outflow facility $. \Delta=$ change. $\mathrm{SEM}=$ standard error of mean.

Table 3 Results of corticosteroid provocative test in eyes at risk of 31 patients

\begin{tabular}{|c|c|c|c|c|c|c|c|c|}
\hline & \multicolumn{3}{|l|}{ Initial } & \multicolumn{3}{|l|}{ Final } & \multirow{2}{*}{$\begin{array}{l}\Delta P \\
P_{2}-P_{1}\end{array}$} & \multirow{2}{*}{$\begin{array}{l}\Delta C \\
C_{2}-C_{1}\end{array}$} \\
\hline & $P_{1}$ & $C_{1}$ & $\mathrm{Po} / \mathrm{c}$ & $P_{2}$ & $C_{2}$ & $P o / c$ & & \\
\hline $\begin{array}{l}\text { Mean } \\
\text { SEM }\end{array}$ & $\begin{array}{c}17 \cdot 2 \\
0 \cdot 50\end{array}$ & $\begin{array}{l}0 \cdot 27 \\
0 \cdot 01\end{array}$ & $\begin{array}{l}73 \\
3.84\end{array}$ & $\begin{array}{c}19.5 \\
0.64\end{array}$ & $\begin{array}{l}0.24 \\
0.02\end{array}$ & $\begin{array}{c}106 \\
10 \cdot 4\end{array}$ & $\begin{array}{r}+2 \cdot 23 \\
0.47\end{array}$ & $\begin{array}{r}-0.03 \\
0.02\end{array}$ \\
\hline
\end{tabular}

Abbreviations as in Table 2. 
Table 4 Results of corticosteroid provocative test in eyes with closed-angle glaucoma and comparison with Becker's results

\begin{tabular}{|c|c|c|c|c|c|c|}
\hline & $\begin{array}{l}\text { No. of eyes } \\
\text { provoked }\end{array}$ & $\begin{array}{l}\text { No. of } \\
\text { positive test }\end{array}$ & $\%$ Responders & $\begin{array}{l}\text { Mean } \\
\Delta P(m m H g)\end{array}$ & $\begin{array}{l}\text { Mean } \\
\Delta C\end{array}$ & $\begin{array}{l}\text { Mean } \\
\% \Delta C\end{array}$ \\
\hline \multicolumn{7}{|l|}{ Present study } \\
\hline Chronic & 1 & 1 & $100 \%$ & 10 & -0.04 & $-25 \%$ \\
\hline Intermittent & 10 & 8 & $80 \%$ & $12 \cdot 2$ & -0.04 & $-26 \cdot 2 \%$ \\
\hline Acute & 37 & 22 & $59 \%$ & $7 \cdot 38$ & -0.04 & $-19 \%$ \\
\hline Total & 48 & 31 & $65 \%$ & $8 \cdot 44$ & -0.04 & $-21 \%$ \\
\hline Becker $^{12}$ & 10 & 2 & $20 \%$ & 3.9 & -0.04 & $-19 \%$ \\
\hline
\end{tabular}

Abbreviations as in Table 2.

classified into chronic, acute, and intermittent. Of the 48 eyes provoked 1 had chronic closed-angle glaucoma, 37 acute closed-angle glaucoma, and 10 intermittent closed-angle glaucoma. The number of positive corticosteroid provocative tests in each of these classes was 1,22 , and 8 respectively.

The mean change in $C$ value for each of the 3 classes of closed-angle glaucoma was $-0 \cdot 04$. When this was considered in relation to the pretest $C$ value, it represented a reduction in outflow facility of $25 \%$ for the eyes with chronic closed-angle glaucoma, $19 \%$ for the eyes with acute closed-angle glaucoma, and $26.2 \%$ for the eyes with intermittent closed-angle glaucoma.

The overall mean $\Delta \mathrm{P}$ for the 48 eyes was +8.44 $\mathrm{mmHg}$, and this was accompanied by an overall mean change in outflow facility $(\Delta C)$ of -0.04 , a reduction equivalent to $21 \%$.

These results are summarised in Table 4 and compared with Becker's results. ${ }^{12}$

\section{GROUP B}

Three of the 31 eyes at risk of developing glaucoma $(9.7 \%)$ showed a positive response, 2 with a change in pressure of $6 \mathrm{mmHg}$ and the third with $\Delta \mathrm{P} 10 \mathrm{mmHg}$.

The mean $\Delta \mathrm{P}$ for the 31 eyes at risk was $+2 \cdot 23$ $\mathrm{mmHg}$ and the mean $\Delta \mathrm{C}$ is -0.03 , equivalent to a reduction in outflow facility of $10 \%$.

These results are compared with Kitazawa's ${ }^{14}$ in Table 5.

\section{STATISTICAL ANALYSIS}

Nonparametric statistical tests were employed to analyse the data on pressure change obtained from this study for the following reasons: (1) Limited knowledge about the population parameters. For example, the frequency distribution of corticosteroid pressure response is debatable. Armaly ${ }^{40}$ and Becker $\$ 21$ both observed a trimodal frequency distribution, but Schwartz et al. ${ }^{15}$ found a near normal distribution with a simple skewness. (2) It is important that the conclusions from this study apply generally rather than only to a specific sample. (3) Some of the data are classificatory and therefore not amenable to analysis by the Students $t$ test (4) Because the numbers are large in this study, the power of the nonparametric tests to reject the null hypothesis becomes comparable with that of the parametric tests.

The data on outflow facility are subjected to parametric statistics because there is no reason to presume that the corticosteroid-induced change in their value is in any way genetically influenced, although it has been suggested that outflow facility is genetically determined. ${ }^{16}$

The statistical analysis of the data from this study and the testing of the hypotheses formulated as a logical consequence of the results are summarised in Table 6.

\section{Discussion}

The prevalence of corticosteroid-induced ocular hypertension in eyes with closed-angle glaucoma is much higher than has been previously reported. $65 \%$ of the $\mathbf{4 8}$ eyes with closed-angle glaucoma in this study had a positive corticosteroid provocative test, and this figure approaches the percentage of responders in primary open-angle glaucoma as cited

Table 5 Results of corticosteroid provocative test in eyes at risk of developing closed-angle glaucoma compared with results of Kitazawa's study ${ }^{12}$

\begin{tabular}{|c|c|c|c|c|c|c|}
\hline Eyes at risk & $\begin{array}{l}\text { No. of eyes } \\
\text { provoked }\end{array}$ & $\begin{array}{l}\text { No. of } \\
\text { positive test }\end{array}$ & $\begin{array}{l}\% \\
\text { Responder }\end{array}$ & $\begin{array}{l}\text { Mean } \\
\Delta P(m m H g)\end{array}$ & $\begin{array}{l}\text { Mean } \\
\Delta C\end{array}$ & $\begin{array}{l}\text { Mean } \\
\% \Delta C\end{array}$ \\
\hline $\begin{array}{l}\text { Present study } \\
\text { Kitazawa }^{14}\end{array}$ & $\begin{array}{l}31 \\
15\end{array}$ & $\begin{array}{l}3 \\
0\end{array}$ & $\begin{array}{l}9 \cdot 7 \% \\
0 \%\end{array}$ & $2 \cdot 23$ & -0.03 & $-10 \%$ \\
\hline
\end{tabular}

*Figures not available but stated to be not statistically significant. Abbreviations as in Table 2. 
Table 6 Statistical analysis of data and hypotheses

\begin{tabular}{|c|c|c|}
\hline Parameter/hypothesis & Statistical test & $\begin{array}{l}\text { Level of } \\
\text { Significance }\end{array}$ \\
\hline $\begin{array}{l}\text { 1. } \Delta \mathrm{P} \text { closed-angle glaucoma eyes } \\
\text { 2. } \Delta \mathrm{C} \text { closed-angle glaucoma eyes } \\
\text { 3. } \Delta \mathrm{P} \text { eyes at risk } \\
\text { 4. } \Delta \mathrm{C} \text { eyes at risk } \\
\text { 5. There is a difference in the corticosteroid pressure response in } \\
\text { closed-angle glaucoma eyes and eyes at risk } \\
\text { 6. There is a difference in the distribution of pressure response } \\
\text { to corticosteroids in closed-angle glaucoma eyes and normal eyes } \\
\text { (Armaly/Becker) }\end{array}$ & $\begin{array}{l}\text { Wilcoxon }(z=-5 \cdot 84) \\
\text { Correlated } t \text { test }(t=-4 \cdot 0) \\
\text { Wilcoxon }(z=-3 \cdot 52) \\
\text { Correlated } t \text { test }(t=-1 \cdot 50) \\
\text { Mann-Whitney U test (corrected for tied } \\
\text { ranks } z=6 \cdot 22) \text { cf. } t \text { test }(t=5 \cdot 45) \\
\text { Present study vs. Armaly } x^{2}=12 \cdot 11 \\
\text { Present study vs. Becker } x^{2}=12 \cdot 2\end{array}$ & $\begin{array}{l}p<0.00001 \\
p<0.001 \\
p<0.0005 \\
\text { Not significant } \\
p>0.1 \\
p<0.0001 \\
p<0.001 \\
p<0.01 \\
p<0.01\end{array}$ \\
\hline
\end{tabular}

Abbreviations as in Table 2.

by several workers-Nordmann et al. ${ }^{1} 80 \%$; Becker and $\mathrm{Hahn}^{5}$ 92\%; Armaly ${ }^{2} 92 \%$. Kitazawa's ${ }^{14} 100 \%$ response in 10 patients with primary open-angle glaucoma is excluded because antiglaucoma therapy was discontinued 7-14 days before the corticosteroid provocative test, and the pressure change in these eyes must therefore be subject to doubt as to whether it was induced entirely by the topical corticosteroids.

The common factor to the 3 groups of eyes with closed-angle glaucoma is an angle-closing mechanism (partial angle closure). Because the presentation of acute closed-angle glaucoma is dramatic, the opportunity for further episodes of angle closure is terminated early by performing a peripheral iridectomy. It is not unreasonable to assume that patients in the other 2 groups-chronic and intermittent-will have had a prolonged episode or several episodes of partial angle closure before the diagnosis was made, because of the less dramatic mode of presentation. The inference from this is that there is a positive correlation between the episodes of partial angle closure and corticosteroid pressure response (see Table 4).

The importance of partial angle closure was given prominence by Mapstone ${ }^{17-19}$ when he wrote, 'Acute closed-angle glaucoma is merely an incident (but an obvious one) in the evolution of a disease process that can have other more subtle consequences too. ${ }^{17} \mathrm{He}$ had earlier provided evidence to support the hypothesis that intermittent partial angle closure is one of the causes of ocular hypertension ${ }^{18}$ and had shown that partial angle closure could be demonstrated in some eyes with apparent open-angle glaucoma. ${ }^{19}$ An obvious question from this which begs for answer is whether the high prevalence of corticosteroid response in patients with primary open-angle glaucoma and ocular hypertension is in any way related to partial angle closure. An attempt to answer this question now without justifying the inference made earlier would be most inappropriate. Suffice it to say at this stage that the answer to that question, if favourable, will be of some clinical relevance.

The inference that there is a positive correlation between the episodes of partial angle closure and corticosteroid pressure response is almost impossible to justify because the former parameter cannot be quantified. But what is amenable to experimental testing is whether eyes that have sustained a form of closed-angle glaucoma behave differently from normal eyes in their response to topical corticosteroids. The results of corticosteroid provocative tests in eyes with closed-angle glaucoma from this study are compared with Armaly's and Becker's results in normal eyes in Table 7. There is a highly significant difference $(p<0.01)$ in the distribution of corticosteroid pressure response as shown in Table 6, no. 6 , and this can be attributed to the closed-angle glaucoma. The alternative explanation is that both closed-angle glaucoma and corticosteroid pressure

Table 7 Comparison of corticosteroid response in closed-angle glaucoma eyes and normal eyes

\begin{tabular}{lllllc}
\hline Study & Number & Parameter & Low & Intermediate & High \\
\hline Present study (closed-angle glaucoma eyes) & 48 & & $17(35 \%)$ & $24(50 \%)$ & $7(15 \%)$ \\
$\quad$ vs. & 80 & $\Delta \mathrm{P}$ & $53(66 \%)$ & $23(29 \%)$ & $4(5 \%)$ \\
$\begin{array}{l}\text { Armaly }{ }^{20} \text { (normal eyes) } \\
\text { Present study (closed-angle glaucoma eyes) } \\
\quad \text { vs. }\end{array}$ & 48 & & $10(21 \%)$ & $21(44 \%)$ & $17(35 \%)$ \\
Becker $^{21}$ (normal eyes) & 50 & FP & $35(70 \%)$ & $13(26 \%)$ & $2(4 \%)$ \\
\hline
\end{tabular}

$\Delta \mathrm{P}=$ change in pressure. $\mathrm{FP}=$ final pressure. 
response could be due to a third common factor.

The corticosteroid pressure response in the 31 eyes at risk is in close agreement with Kitazawa's result in 10 patients, and the percentage of responders is similar to that reported for normal eyes by some observers. ${ }^{6}$ Comparing this with the response in closed-angle eyes in this study (see Table 6, row 5) we find a highly significant difference $(p<0 \cdot 0001)$.

From these comparisons it becomes apparent that eyes with closed-angle glaucoma behave differently from normal eyes and eyes at risk in their pressure response to topical corticosteroids. Because of the nature of the samples used in testing this hypothesis, the genetic influence on the high prevalence of corticosteroid-induced ocular hypertension in eyes with closed-angle glaucoma (65\%), and on the highly significant difference in response when compared with normal eyes and eyes at risk, cannot be properly assessed and eliminated. Yet because of the clinical significance of this hypothesis it is important that the genetic influence be eliminated. This can be done simply by using matched pairs of eyes which are provided by patients with unilateral closed-angle glaucoma. Any difference between the paired eyes would be a reflection of the effect of the closed-angle glaucoma and not of the genetic composition of the patient, as this will be common to both eyes. This is the subject of the second part of this paper. Armaly ${ }^{2}$ used this experimental model in 1967 but with respect to traumatic angle recession glaucoma in 11 patients. He concluded that the response to topical dexamethasone did not reflect the local changes in the glaucomatous eye but the genotype of the patient.

The following conclusions are drawn: (1) The prevalence of corticosteroid-induced ocular hypertension in closed-angle glaucoma eyes is higher than previously reported. (2) Eyes at risk of developing closed-angle glaucoma (because the fellow eyes had spontaneous closed-angle glaucoma) have a much lower prevalence of positive corticosteroid pressure response. (3) There is a marked difference between the corticosteroid pressure response of eyes with closed-angle glaucoma and normal eyes or eyes at risk.

\section{References}

1 Nordman J, Lobstein A, Gerhard JP, et al. Le test à la cortisone dans le glaucome simple à champs visuel normal. Ophthalmologica 1965; 150: 46-56.

2 Armaly MD. Inheritance of dexamethasone hypertension and glaucoma. Arch Ophthalmol 1967; 77: 747-51.

3 Spaeth GL. Effects of topical dexamethasone on intraocular pressure and water drinking test. Arch Ophthalmol 1966; 76: $772-83$.

4 Armaly MF. The heritable nature of dexamethasone-induced ocular hypertension Arch Ophthalmol 1966; 75: 32-6.

5 Becker B, Hahn KA. Topical corticosteroids and heredity in primary open angle glaucoma. Am J Ophthalmol 1964; 57: 543-51.

6 François J. Corticosteroid glaucoma. Ann Ophthalmol 1977; 9: 1075-80.

7 Becker B, Chevrette L. Topical corticosteroid testing in glaucoma siblings. Arch Ophthalmol 1966; 76: 484-7.

8 Dean GO, Dentsh AR, Hiatt RL. The effect of dexamethasone in borderline ocular hypertension. Ann Ophthalmol 1975; 9: 193-8.

9 Levene R, Wigdor A, Edelstein A, Baum J. Topical corticosteroid in normal patients and glaucoma suspects. Arch Ophthalmol 1967; 77: 593-7.

10 Miller SJH, Paterson G. Studies on relatives of glaucoma patients. Br J Ophthalmol 1962; 46: 513-22.

11 Patterson G. Studies of the response to topical dexamethasone of glaucoma relatives. Trans Ophthalmol Soc UK 1965; 85: 295-305.

12 Becker B. The effect of topical corticosteroids in secondary glaucomas. Arch Ophthalmol 1964; 72: 769-71.

13 Masuda $H$. The steroid ocular pressure response in the glaucomatous eyes. Nippon Ganka Gakkai Zasshi 1969; 73: 2060-9.

14 Kitazawa Y. Primary angle-closure glaucoma. Corticosteroid responsiveness. Arch Ophthalmol 1970; 84: 724-7.

15 Schwartz JT, Reuling FH, Feinleib M, Garrison RJ, Collie DJ. Twin study on ocular pressure after topical dexamethasone. I. Frequency distribution of pressure response. Am J Ophthalmol 1973; 76: 126-36.

16 Armaly MF, Monstavieius BF, Sayegh RE. 1. Ocular pressure and aqueous outflow facility in siblings. Arch Ophthalmol 1968; 80: $354-60$.

17 Mapstone $R$. The role of provocative tests in closed-angle glaucoma. Res Clin Forums 1980; 2: 67-71.

18 Mapstone $\mathrm{R}$. Mechanisms in ocular hypertension. $\mathrm{Br} J$ Ophthalmol 1979; 63: 325-30.

19 Mapstone $\mathrm{R}$. Mechanisms in open-angle glaucoma. $\mathrm{Br} J$ Ophthalmol 1978; 62: 275-82.

20 Armaly MF. Statistical attributes of the steroid hypertensive response in the clinically normal eye. I. The demonstration of the three levels of response. Invest Ophthalmol Visual Sci 1965; 4: 187-97.

21 Becker B. Intraocular pressure response to topical corticosteroids. Invest Ophthalmol Visual Sci 1965; 4: 198-205. 